\title{
AFFORESTATION: ECOLOGY IN THE WEST SWALE
}

\section{Julia Adamson}

Friends of the Saskatoon Afforestation Areas Inc.

210 Appleby Court

Saskatoon, SK S7M 4B2

An ancient Pleistocene era river was created from a roaring, rushing surge of water as the shoreline of the glacial meltwater lake collapsed. This glacial spillway, the Yorath Island Spillway, is now referred to as the West Swale. The remains of this river can still be seen on satellite maps as a unique ecosystem connecting the North and South Saskatchewan River valleys. Richard St. Barbe Baker Afforestation Area (326 acres) and George Genereux Urban Regional Park (147.9 acres) are two afforestation areas in the West Swale.

The Saskatoon Nature Society has included Richard St. Barbe Baker Afforestation Area in its book $A$ Guide to Nature Viewing Sites in and Around Saskatoon ${ }^{1}$. The mixed deciduous and evergreen forest areas provide a rare treat for visitors and naturalists as they are situated in the "moist mixed grassland" ecoregion associated with the grasslands and prairie regions of North America. Typically, mixed forests only appear hundreds of miles away as the province of Saskatchewan transitions to the aspen parkland and then to the boreal ecoregion.

The Saskatoon afforestation areas feature 17 acres of wetlands amid the naturalized and native woodlands and provide important habitat for a number of species. The Horned Grebe and Barred Tiger Salamander are listed as a species of special concern by the Committee on the Status of Endangered Wildlife in Canada — an Independent Advisory Panel to the Minister of Environment and Climate Change. The Rednecked Phalarope, Baird's Sparrow and Grasshopper Sparrow are special concern; Bobolink and Bank Swallow are listed as threatened nationally under the federal Species at Risk

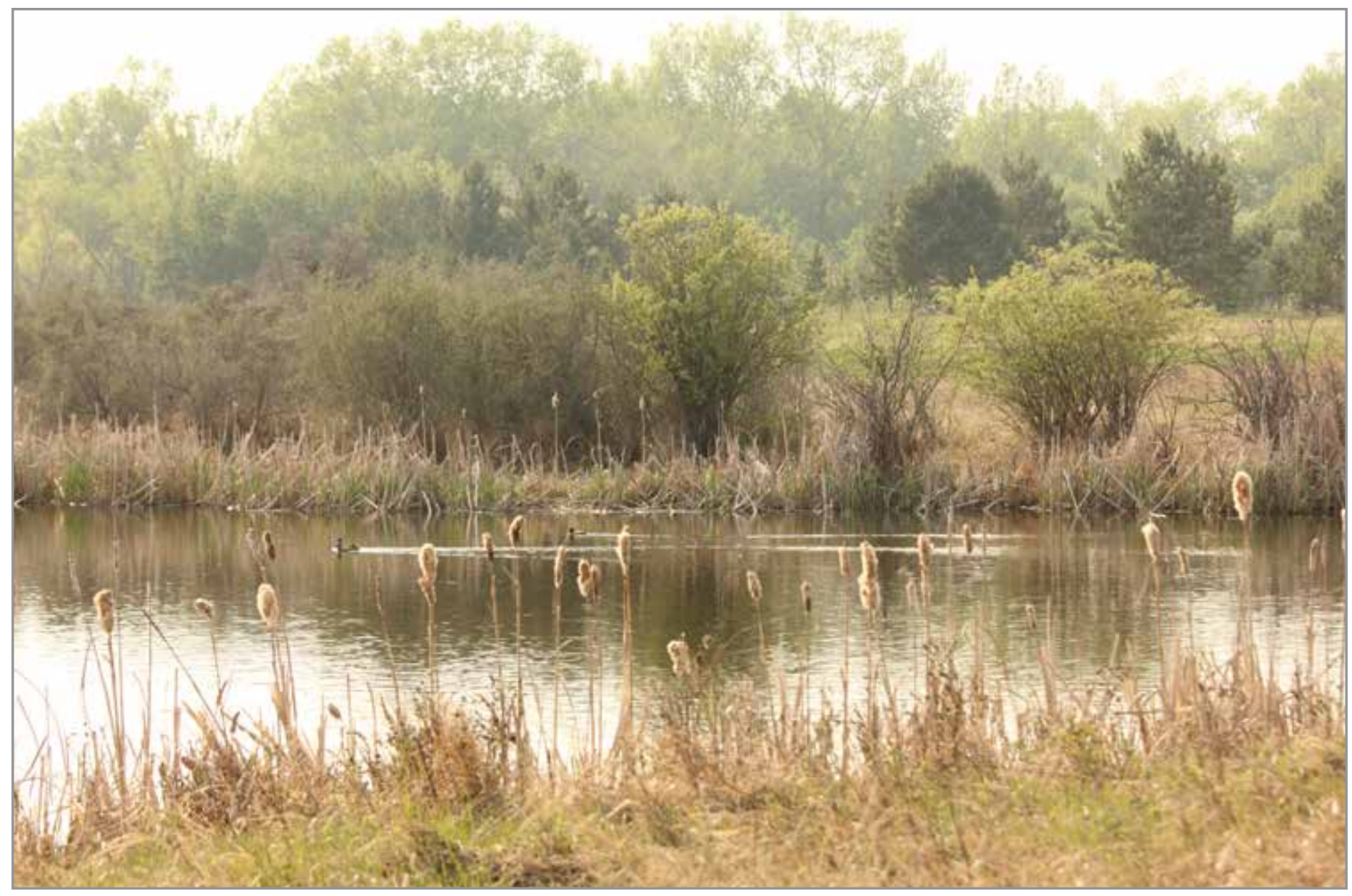

The Richard St. Barbe Baker Afforestation Area contains West Swale permanent wetlands of Chappell Marsh. May 2016. Photo credit: Julia Adamson. 


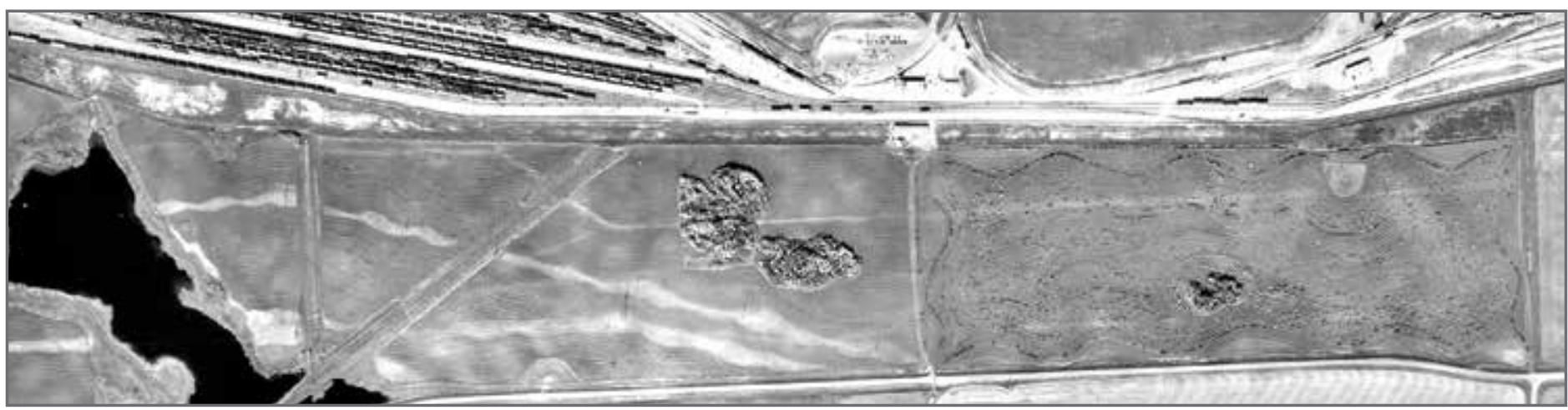

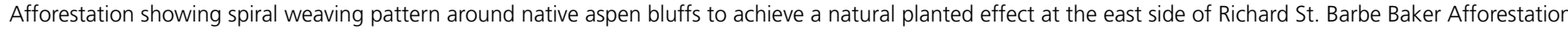
Area. Courtesy of the City of Saskatoon Archives \#1103-11-007-001 Chappell Yards and south (1975)

Act SARA Schedule 1. Protecting critical habitat is thus a key concern. Colonial nesting birds include Blackcrowned Night Heron, Great Blue Heron and American White Pelican. A more detailed bird listing is registered on eBird.

According to Chet Neufeld, Executive Director of the Native Plant Society, referencing the provincial rare species database, "there have been occurrences of endangered
Whooping Cranes observed near the area in 2017 and an occurrence of Small Yellow Lady's-slipper (date unknown)" (email December 25, 2019). A Saskatoon Nature Society Field Trip on June 14, 2017 confirmed the Lady's-slipper sighting on the east side of the afforestation area.

The afforestation areas have been popular with the Saskatoon Nature Society for monitoring the bat population, as well as for banding nocturnal and diurnal raptors. A common bird sighting area is on Township Road 362A as the wetland waterfowl habitat has been dissected by the road. To the north of this road are the wetlands of the Richard St. Barbe Baker Afforestation Area, and to the south is Chappell Marsh Conservation Area.

This area is also unique for scientific study, as it was purchased

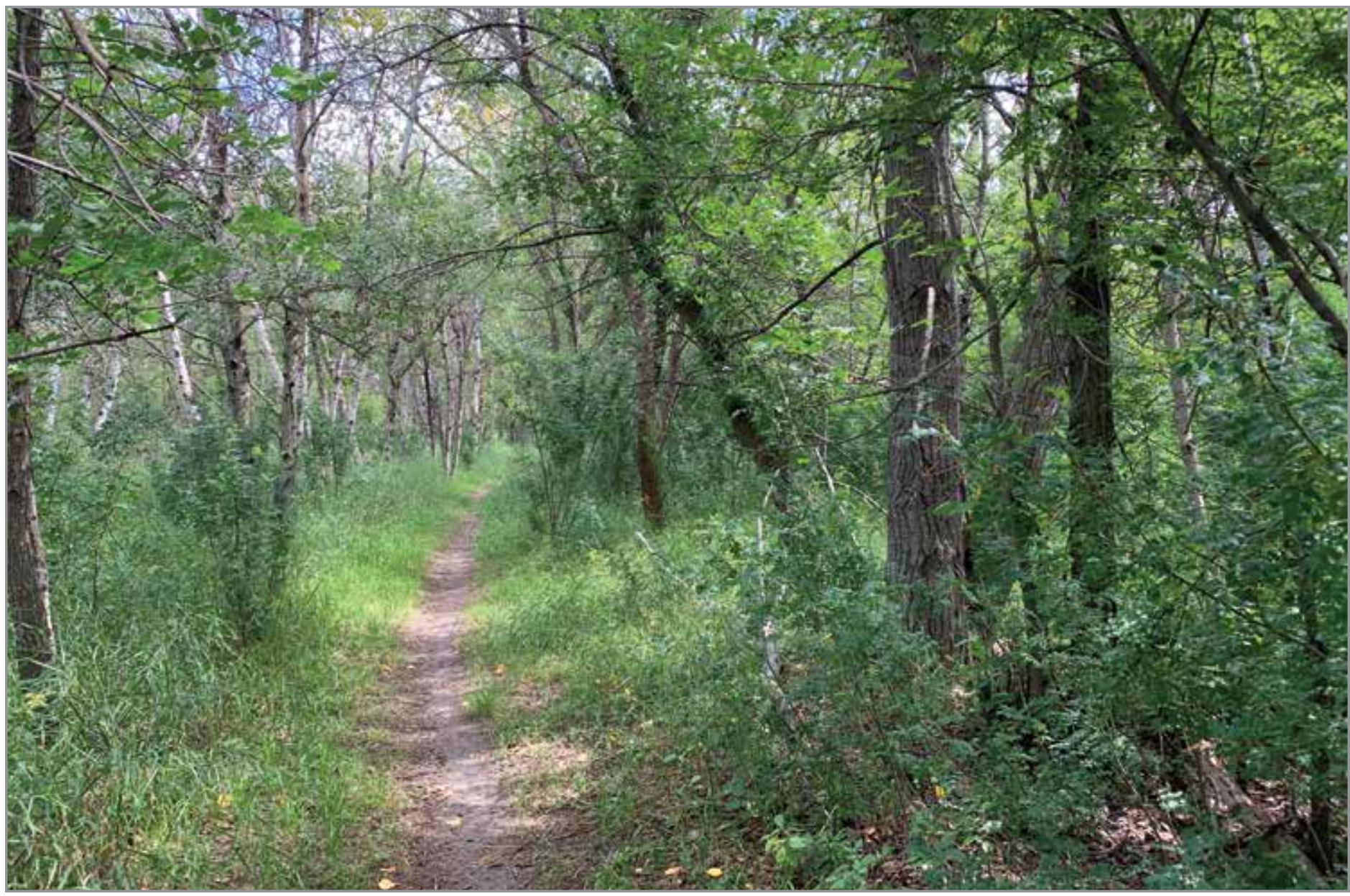

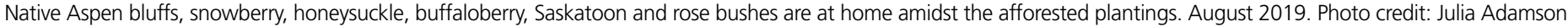


in 1960 by the city and afforested in 1972. Indeed, there is a project currently taking place in George Genereux Urban Regional Park by the upper level Agriculture and Bioresources landscape and vegetation management class at the University of Saskatchewan ( $U$ of S).

The afforestation areas have been isolated for half a century as a semi-wilderness habitat. These urban regional parks, which began as tree nurseries during the 'Green Survival Program' of the 1970s, are slowly reverting back to an aspen forest ecosystem with native forbes and grasses from the moist mixed grasslands.

A recent biography by Paul Hanley has been written entitled Man of the Trees. Richard St. Barbe Baker, the First Global Conservationist. The foreword is by HRH The Prince of Wales and the introduction is by Jane Goodall. In it, Hanley states that "Baker was primarily a catalyst, a wedge, a collaborator. He accomplished what he did mainly by inspiring others. His modus operandi was often reflected in their work." 2

In 1969, in recognition of his conservation efforts, Baker was made the first Honorary Life Member of the World Wildlife Fund. ${ }^{3} \mathrm{He}$ also received an honourary Doctor of Laws from the $U$ of $S$, and was presented with the Order of the British Empire.

Changes surround the afforestation areas as there are plans to assimilate them directly into the urban design. The Blairmore Sector Plan, an area of planned city growth, will accommodate eight future neighbourhoods with between 50,000 to 70,000 residents who will live next door to the afforestation areas, and which will join the existing immediate neighbours of Montgomery Place and Cedar Villa Estates. ${ }^{4}$ To support this population influx, there will be a new employment sector to the other side of the afforestation area urban regional parks.

Both afforestation areas are located within the city limits alongside the boundary between the city and Rural Municipality of Corman Park 344. The planners for the Saskatoon North Partnership for Growth (P4G) partnering municipalities have long-range goals for a rural commercial/industrial area around George Genereux Urban Regional Park. That said, the P4G region seeks to "protect the region's natural beauty, ecology and heritage" as the "region's

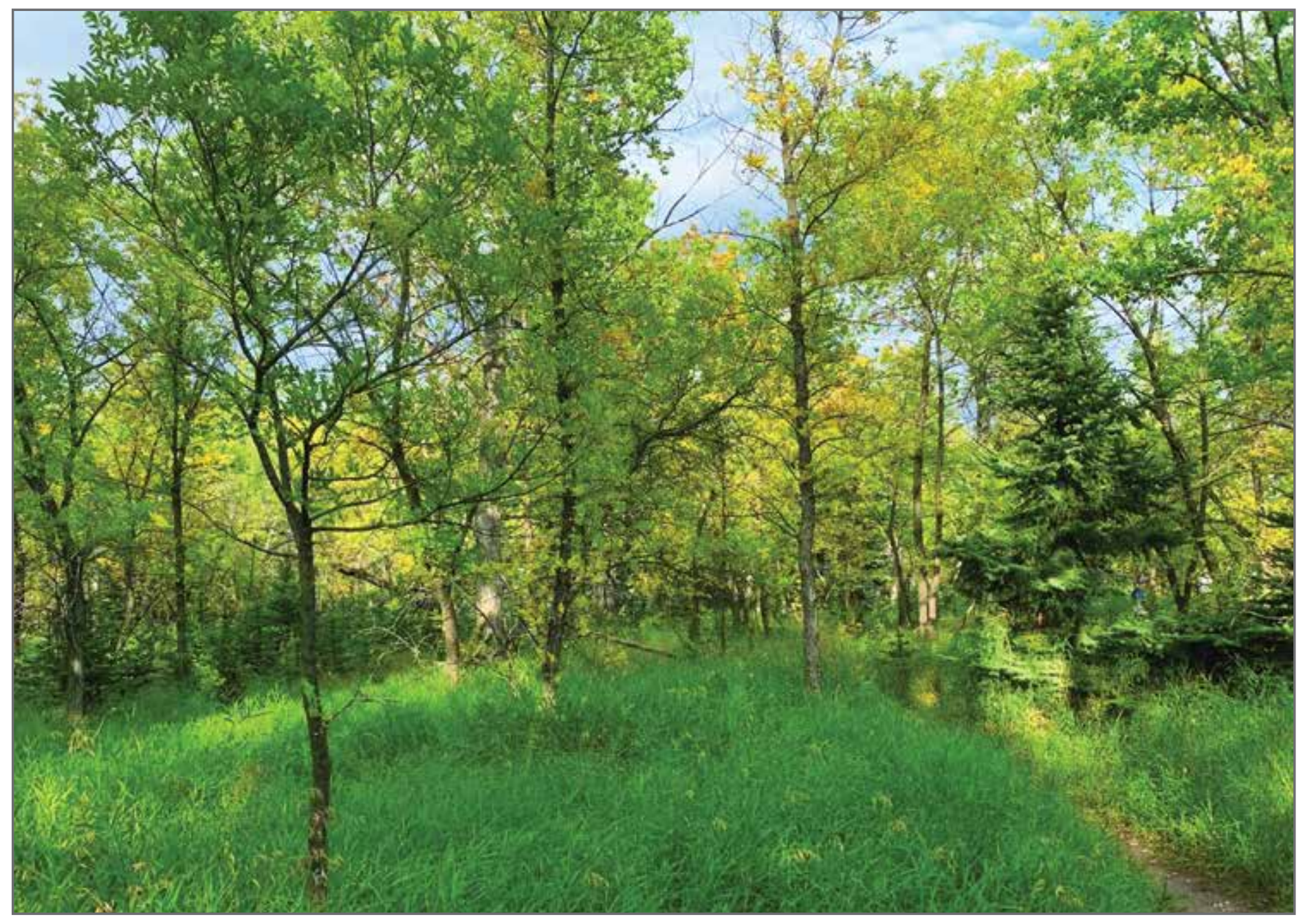

Richard St. Barbe Baker Park September 2019. Photo credit: Julia Adamson. 
population could reach 500,000 in the next 20 years and could grow to $1,000,000$ people in the next 60 years." ${ }^{5}$ The $P 4 G$ intends at this time to "not interfere with key natural areas" and has allocated conservation and drainage zones as a green network study area, which will provide connectivity between the afforestation areas, the West Swale and the South Saskatchewan River. ${ }^{5}$

A submission has been put forth to declare George Genereux Urban Regional Park, Richard St. Barbe Baker Afforestation Area and the West Swale as municipal heritage sites. There is an abundance of natural, aesthetic, environmental, cultural, historical, geological and geographical heritage importance in these places and the submission is currently under review by City of Saskatoon administration.
To assist in the City of Saskatoon's strategic goal of environmental leadership, the Friends of the Saskatoon Afforestation Areas Inc. has formed as a non-profit registered charity to enhance the safety of these urban regional parks and to protect these parcels of land that were 'preserved in perpetuity' by city council in 1972 . The goals and purpose of the Friends aims to protect the environment for the biodiversity at the afforestation areas, and seeks to engage community citizens with information about the cultural, aesthetic, geological, geographical, historical (Old Bone Trail), and natural (flora and fauna) heritage aspects of the areas.

For further information, please visit https://stbarbebaker.wordpress. com/ or email us at FriendsAfforestation@gmail.com.
1. Bruce, Donna; Leighton, Anna (2016). A guide to nature viewing sites in and around Saskatoon (third ed.). Saskatoon, Saskatchewan: Saskatoon Nature Society and Nature Saskatchewan. p. 161.

2. Hanley, Paul. (2018) Man of the Trees Richard St. Barbe Baker the First Global Conservationist. University of Regina Press. Regina, SK. p. 270.

3. Allen, Camilla. (2017) The Man of the Trees Richard St. Barbe Baker. Landscapes Paysages. WinterlHiver 2017 Vol. 19_no.4. p. 60. Retrieved December 10, 2019.

4. City of Saskatoon Planning \& Development Branch Future Growth Section (September 2010), "2.0 Background",

Blairmore Sector Plan (PDF), p. 1, File 411012-3, retrieved December 10, 2019

5. Saskatoon North Partnership for Growth Regional Plan (Feb 2016). Welcome to the Regional Plan Open House (PDF). P4G. Retrieved December 10, 2019.

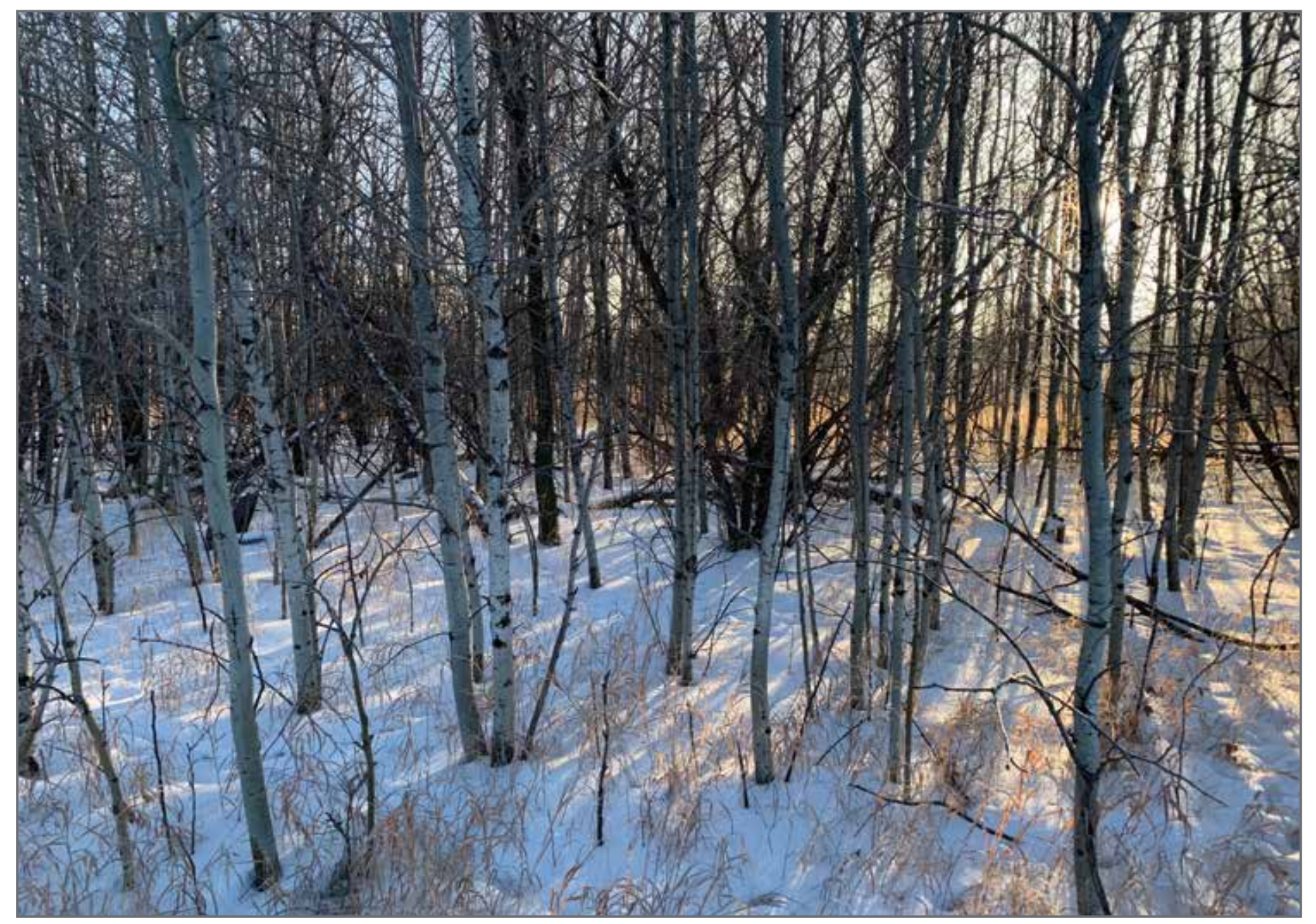

George Genereux Urban Regional Park. Winter 2018. Photo credit: Julia Adamson. 